\section{Anatomical and functional outcomes in contusion injuries of posterior segment}

Eye (2011) 25, 1105; doi:10.1038/eye.2011.161

Correction to: Eye (2011) 25, 1050-1056; doi:10.1038/eye.2011.118; published online 27 May 2011

Since the publication of the above article, the authors have noticed that the first author's
FC Erdurman, G Sobaci, CH Acikel, MO Ceylan, AH Durukan and $V$ Hurmeric

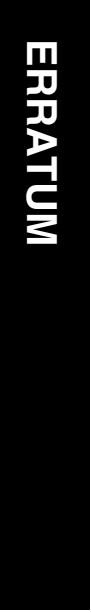

The typesetters would like to apologise for this mistake. 